\title{
Toughness Behaviour in Armour Steel Welds
}

\author{
Aleksandar CABRILO, Katarina GERIC, Olivera KLISURIC, Miroslav CVETINOV
}

\begin{abstract}
The process of welding armor steel is a complex process not only due to high percentage of carbon in the base metal, but also because of possible welding faults, appearing in the weld metal zone in the form of cracks and pores. Austenitic filler material is traditionally used for welding armor steels, thus avoiding the negative effect of hydrogen content due to slow diffusion towards the sensitive fusion line. For heavy structural engineering such as armored military vehicles, which are frequently under the effect of impact and dynamic load, it is important to know the dynamic properties of the most sensitive area of welded joints, the weld metal zone. Instrumented impact testing was made on Charpy $\mathrm{V}$ specimens. The impact energy results were $56 \mathrm{~J}$ and $29 \mathrm{~J}$ for crack initiation and propagation, respectively. Due to a significant interest in quantification of material resistance to crack initiation and propagation, the fatigue crack growth rate was measured in the welded metal zone, while the resistance to crack growth in the weld metal was tested by the amount of austenite transformed into martensite. Accordingly, the threshold stress concentration factor was $10 \mathrm{MPa} \mathrm{m}^{1 / 2}$. XRD spectral analysis revealed direct transformation of $\gamma$ - austenite into $\alpha^{\prime}$ - martensite.
\end{abstract}

Keywords: armor steel; austenitic stainless steel and martensitic transformation; fatigue crack growth; instrumented Charpy tests

\section{INTRODUCTION}

Armor steel belongs to the ultra-high tensile strength and hardness group of steels. The welding of armor steel is complicated due to the high percentage of carbon content in the base metal and the presence of faults in the form of cracks and pores [1] in the weld metal zone, whereby fractures may be initiated in the weld metal. Austenitic filler material is traditionally used for armor steel welding because of hydrogen dilution improved in an austenitic phase [2]. This avoids hydrogen content negative effects, such as slow diffusion towards the sensitive fusion line and crack formation [3]. The filler material, in armor steel welded joints has lower mechanical properties than the base material, i.e. the filler material is the weakest point of the welded joint [4]. After the welding process, solidification cracking may result from high thermal expansion of the austenitic stainless steel [5] and invisible defects may be created in the weld metal zone [6]. Heat input and cooling time at $650-850{ }^{\circ} \mathrm{C}$ are important issues during austenitic stainless steel multi pass welding. Local sensitized zones can be developed as a result of chromium carbide formation at grain boundaries [7].

For heavy structural engineering, such as armored military vehicles frequently being under the effects of impact and variable loads [8], mechanical properties of welded joints and the weld metal zone must be known. Due to variable loads, cracks created in the weld metal may easily propagate towards the sensitive fusion line, followed by their possible rapid growth [9]. The presence of delta ferrite reduces ductility and potentially toughness. In addition, austenite/ferrite boundaries could be preferential sites for the precipitation of $\mathrm{M}_{23} \mathrm{C}_{6}$ type carbides [10]. The impact load is critical for armored vehicles, so the determination of the impact energy required for crack initiation and growth made by instrumented pendulum with Charpy V specimens, is very significant [11].

For armored vehicle structures safe and rational dimensioning, it is necessary to know dynamic effects extreme values and time periods. Therefore, there is a significant interest in material resistance related to crack initiation and propagation, as well as in dynamic force conditions. For the armored military vehicles reliable operation, it is very important to be able to carry out a good risk assessment of existing crack type faults. This can be achieved by fracture mechanic concepts application. A fatigue crack growth rate characteristic in the linear and threshold region in metal weld is considered as an important property, since it shows a fault - tolerant ability of this part of welded joint $[12,13]$.

Although austenitic filler material is used most frequently for welding and has several unusual features including its high manganese content, few articles consider the problem of its mechanical properties. There are numerous studies of fatigue crack growth in austenitic materials, but mainly due to deformation, with only a few investigating austenitic weld metal [14]. Austenitic filler material is unstable and gets transformed into martensite during fatigue crack propagation due to plastic deformation at the crack tip [15]. During the metastable austenite deformation, two types of martensitic structures can be formed: $\varepsilon$ - martensite with hexagonal close packed and $\alpha^{\prime}$ - martensite, with body centered cubic crystal structure. Austenite into martensite transformation is related to the stacking fault energy. If the stacking fault energy is $<20$ $\mathrm{J} / \mathrm{m}^{2}$, transformation proceeds according to the model: $\gamma \rightarrow$ $\varepsilon \rightarrow \alpha$ '. If it is larger, then the direct $\gamma \rightarrow \alpha$ ' transformation occurs [16]. It is known that manganese and nickel stabilize martensite and prevent martensitic transformation. It should be noted that the upper limit of stacking fault energy of austenite-martensite phase transition phase transition varies $[17,18]$. An amount of austenite transformed into martensite is directly related to crack growth resistance in the weld metal [19].

High hardness steels are sensitive to the presence of hydrogen [2]. It is known that hydrogen can enter the steel from various sources, such as the casting or welding process during its exploitation [20]. The hydrogen, present in weld metal, may affect the crack propagation rate [21]. The measurement of diffusible hydrogen content in AWS 307 filler material is necessary in order to investigate its presence and possible effects on crack growth rate.

Welding process and filler material effects on the residual and diffusible hydrogen amount in the weld metal zone were investigated in this work. Particular attention was paid to the weld metal zone, as failure occurs in this 
region. The main goal of this study was to investigate the impact energy by instrumented pendulum and fatigue crack growth in the Paris region. Martensitic transformation effects on fatigue crack growth in the Paris region were investigated by $\mathrm{X}$ - ray diffraction. Fracture surfaces for the impact energy and fatigue crack growth tests were also investigated by Scanning Electron Microscope (SEM). Subsequently, samples in the weld metal region were studied by tensile strength test, hardness measurements, metallography and chemical analysis.

\section{MATERIALS AND EXPERIMENTAL PROCEDURE \\ 2.1 Materials and Welding Process}

Gas metal arc welding (GMAW) and AWS ER307 solid wire is used for welding armor steel Protac 500. Welding direction is parallel to the rolling direction. Cold rolled plates $12 \mathrm{~mm}$ thick are cut to the required dimensions $(250 \times 100 \mathrm{~mm})$, while $\mathrm{V}$ joint under the angle of $55^{\circ}$ is prepared by Water Jet Device Fig. 1. Robot Kuka and Citronix 400A device was used during the welding process testing. Details on welding are shown in the article [21]. Robotic welding is used for human factor effect elimination, in order to allow a fine adjustment of parameters and results repeatability. Wire diameter is 1.0 $\mathrm{mm}$ while Fig. 1 shows V joint dimensions and four - pass welding configuration.
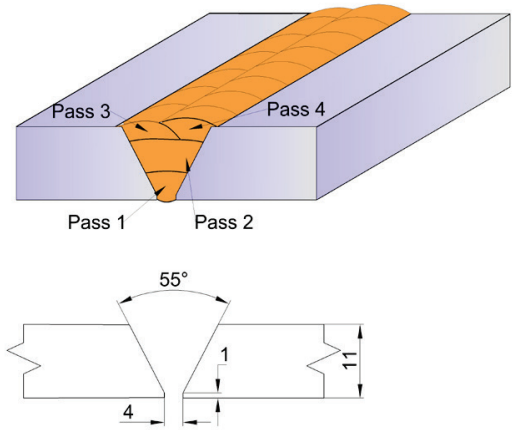

Figure 1 Schematic drawing of edge preparation and welding configuration

Base material chemical composition obtained by spectro - chemical analysis is shown in Tab. 1, while the filler material chemical composition is shown in Tab. 2 . Spectro-chemical analysis was performed after the welding process.
An amount of delta ferrite in austenitic base is determined by Feritscope. Magnetic ferrite mass fraction was measured in three zones of the welded joint: in weld metal root - lower weld metal part, then in filler zone middle weld metal part as well as in cover passes - upper weld metal part.

As for the fatigue crack growth rate test, it is important to obtain the welded joint without porosity and cracks. Therefore, radiographic testing was being performed after the welding proces.

\subsection{Diffused and Retained Hydrogen Measurement}

In order to achieve selected welding parameters, more detailed analysis, the testing included diffused and retained hydrogen quantity in the weld metal zone. For both tests, the method of hot gas extraction (CGHE) was used, while the quantity of hydrogen was measured by gas chromatography. Diffused hydrogen quantity measurement was performed according to EN ISO 3690 [23]. The plate for welded pass application was heated up to $150{ }^{\circ} \mathrm{C}$, in order to simulate real welding conditions. The filler material with welding parameters presented in this study [21] was applied after preheating and putting into the copper clamp, where the copper plate is positioned under the plate and test specimen.

The testing process was repeated for the temperature of $160{ }^{\circ} \mathrm{C}$ to test interpass temperature effects to the diffused hydrogen quantity. Retained hydrogen was measured on the welded joint specimen. Specimen cut position from the weld is shown in Fig. 2. To test the specimen, the hot gas extraction method was applied then. Retained hydrogen quantity was measured by gas chromatograph.

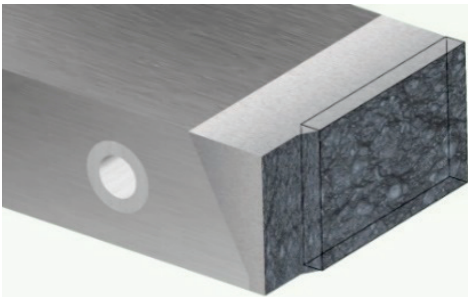

Figure 2 Schematic drawing of test specimen separation position for retained hydrogen testing

Table 1 Chemical composition of the base metal

\begin{tabular}{|c|c|c|c|c|c|c|c|c|c|c|c|c|c|c|c|}
\hline \multirow{2}{*}{ Material } & \multicolumn{15}{|c|}{ Chemical composition (wt. \%) } \\
\hline & $\mathrm{C}$ & $\mathrm{Si}$ & $\mathrm{Mn}$ & $\mathrm{S}$ & $\mathrm{Cr}$ & $\mathrm{P}$ & $\mathrm{Al}$ & $\mathrm{Cu}$ & $\mathrm{Ni}$ & Mo & $\mathrm{V}$ & Sn & $\mathrm{Si}$ & $\mathrm{Mn}$ & $\mathrm{S}$ \\
\hline Protac 500 & 0.27 & 1.07 & 0.71 & 0.001 & 0.64 & 0.009 & 0.054 & 0.28 & 1.09 & 0.296 & 0.039 & 0.011 & 0.27 & 1.07 & 0.71 \\
\hline
\end{tabular}

Table 2 Chemical composition of the filler material

\begin{tabular}{|c|c|c|c|c|c|c|c|c|c|c|c|c|c|c|c|}
\hline \multirow{2}{*}{ Material } & \multicolumn{15}{|c|}{ Chemical composition (wt. \%) } \\
\hline & $\mathrm{C}$ & $\mathrm{Si}$ & $\mathrm{Mn}$ & $S$ & $\mathrm{Cr}$ & $P$ & $\mathrm{Al}$ & $\mathrm{Cu}$ & $\mathrm{Ni}$ & Mo & $\mathrm{V}$ & $\mathrm{Sn}$ & $\mathrm{C}$ & $\mathrm{Si}$ & $\mathrm{Mn}$ \\
\hline ER 307 & 0.08 & 0.89 & 6.29 & 0.001 & 17.76 & 0.014 & 0.01 & 0.08 & 8.24 & 0.13 & 0.03 & 0.011 & 0.08 & 0.89 & 6.29 \\
\hline
\end{tabular}

\subsection{Mechanical Property Tests}

Welded joint tensile strength testing was performed in transverse direction of the weld bead. It should be noted that specimens were cut with Water Jet Device, to eliminate possibilities of thermal effects to high hardness steel. Tensile strength testing was made on servo - hydraulic testing machine Instron 8033 . The loading rate was set as $0.125 \mathrm{~mm} / \mathrm{s}$ until fracture took place. During the tensile test, extensometer was used to monitor and record the stress-strain curves and strain gauge was employed to verify the results obtained by the extensometer. 


\subsection{Metallography and Hardness Testing}

The microstructural examination was performed using a "Leitz-Orthoplan" metallographic microscope and a scanning electron microscope JEOL JSM 6460LV at 25 $\mathrm{kV}$. The samples were ground using SiC papers, polished with a diamond paste and finally etched with a mixture $\mathrm{HCl}$ and $\mathrm{HNO}_{3}$ reagent to reveal the structure.

Microhardness distribution from top to bottom along the centreline of the weld was measured for the purpose of welded metal characterization. Digital Micro Vickers Hardness Tester HVS 1000, Laiznou Huayin Testing Instrument $\mathrm{Co}$, under the load of $500 \mathrm{~g}$, was used in order to measure microhardeness.

The microstructural examination was performed using a "Leitz-Orthoplan" metallographic microscope and a scanning electron microscope JEOL JSM 6460LV at 25 $\mathrm{kV}$. The samples were ground using $\mathrm{SiC}$ papers, polished with a diamond paste and finally etched with a mixture $\mathrm{HCl}$ and $\mathrm{HNO}_{3}$ reagent to reveal the structure.

Microhardness distribution from top to bottom along the centreline of the weld was measured for the purpose of welded metal characterization. Digital Micro Vickers Hardness Tester HVS 1000, Laiznou Huayin Testing Instrument $\mathrm{Co}$, under the load of $500 \mathrm{~g}$, was used in order to measure microhardeness.

\subsection{Instrumented Charpy Tests}

Charpy impact tests in weld metal, Fig. 3, were performed on specimen's size $10 \times 10 \times 55 \mathrm{~mm}^{3}$ at least three times for each datum point at: $20{ }^{\circ} \mathrm{C}, 0{ }^{\circ} \mathrm{C},-20{ }^{\circ} \mathrm{C}$ and $-40^{\circ} \mathrm{C}$. Load-displacement curves were also obtained from the instrumented Charpy impact system attached in to the impact tester. After the test, fracture surface was examined by a SEM to observe fracture modes.

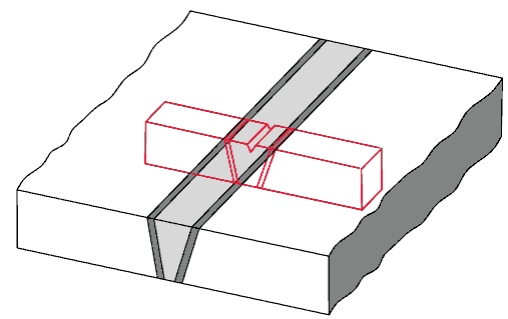

Figure 3 Specimen orientation with respect to the weld axis for instrumented Charpy test

\subsection{Fatigue crack growth test}

Three point bending specimen, SEN (B) was used for testing [24]. The schematic drawing of specimen for fatigue crack growth test is shown in Fig. 4. Specimens were cut by Water Jet Device, to eliminate any possibility of armor steel thermal treatment. After getting final measures in the grinding process, $5 \mathrm{~mm}$ long machined notch was created on specimens in the direction parallel to welding Fig. 5, according to the E-647 standard [25]. The fatigue pre-crack was inserted before the crack growth rate tests, in accordance with ASTM E647 [25]. The length of the fatigue pre-crack was $4.7 \mathrm{~mm}$. The fatigue pre-crack was realized with a high-frequency CRACTRONIC pulsator, at a load ratio $R=0.33$, followed by a constant loading frequency of $170 \mathrm{~Hz}$. Fatigue crack growth rate was tested on high-frequency CRACTRONIC pulsator, the model with force and frequency control of $145 \mathrm{~Hz}$. The constant sinusoidal shape was used, while the testing was made under the load ratio $R=K_{\min } / K_{\max }=0.1$.

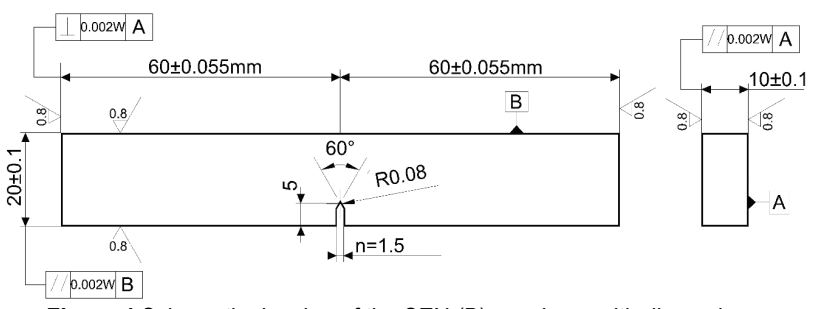

Figure 4 Schematic drawing of the SEN (B) specimen with dimensions

During testing procedure, the crack length was measured by RUMUL RMF A-10 measuring foils. In the course of experiments, the number of cycles for each crack growth of $0.05 \mathrm{~mm}$ was automatically recorded. On the basis of these records, the diagram of $a-N$ was drawn. $a-N$ curves of dependence were used for crack growth rate $d a / d N$ determination.

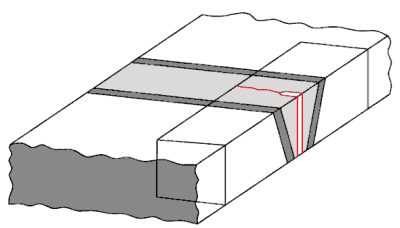

Figure $\mathbf{5}$ Specimen orientation with respect to the weld axis for fatigue crack growth test

For this test, three specimens were used, in same testing conditions and initial loads. The result was average value of three measurements. A fracture surface was analyzed by Scanning Electron Microscope JEOL JSM $6460 \mathrm{LV}$ at $25 \mathrm{kV}$.

\subsection{Quantitative Phase Analysis by X-ray Diffraction}

X-ray diffraction was used to identify a martensitic transformation amount formed during the crack propagation, under the effect of fatigue load. Investigation was undertaken by X-ray diffraction in Brag-Brentano $\theta: 2 \theta$ reflection geometry, at a room temperature. Diffractograms were recorded on a Philips X-ray diffractometer having a copper tube PW 1830 generator, a PW 1820 goniometer fitted with a post-diffracted graphite monochromator and a scintillation detector attached to a PW 1710 controller $(30 \mathrm{kV}, 30 \mathrm{~mA}$ generator settings, $\mathrm{CuK} \alpha$ radiation). $\mathrm{LaB}_{6}$ was used as an external standard for peak position calibration and for instrumental peak broadening assessment. XRD data were collected over the $2 \theta$ range of $40^{\circ}$ to $60^{\circ}$, with a step size of $0.05^{\circ}$ and an exposition time of $2 \mathrm{~s}$ per step.

Martensite to austenite ratio was measured on the fracture surface. After the analysis, the $0.05 \mathrm{~mm}$. thick layer was removed, upon which the measurement procedure of austenitic transformation amount was repeated. The repeatability continued to $25 \%$ of the austenitic transformation value in martensite. An experimental XRD patterns decomposition (profile fitting) was performed using pseudo - Voigt function on each diffraction peak and linear function on background 
radiation. For quantitative phase analysis RIR method was employed [26]. The RIR method scales all diffraction data to the standard. By convention, corundum is used as an international reference. The scale factor, $I / I_{c}$, was experimentally determined from the pattern strongest line ratio, $I$, to the corundum $I_{c}$ strongest line intensity, in a $50 / 50$ weight mixture.

As to determination of martensite and austenite phases weight contents, their scaling factors were obtained from the ICDD PDF-2 database (PDF 41293, PDF 441292, PDF 897245 and PDF 330397). Due to the heavy peak overlapping in the $43^{\circ}-44.5^{\circ} 2 \theta$ region, this method could only be employed on the second most intense peak of both martensite, $I_{2 \text { mart }}$, and austenite, $I_{2 \text { aust }}$, at $\sim 45.0^{\circ} 2 \theta$ [27] and $\sim 50.7^{\circ} 2 \theta[28,29]$, respectively. Intensity ratios of the two strongest lines for martensite, $\left(I / I_{2}\right)_{\text {mart }}$, and austenite phase, $\left(I / I_{2}\right)_{\text {aust }}$, were thus obtained from the same database. The following equation served for calculation to be done:

$X_{\text {mart }} \cdot I_{2 \text { aust }} \cdot\left(I / I_{2}\right)_{\text {aust }} \cdot\left(I / I_{\mathrm{c}}\right)_{\text {mart }}=X_{\text {aust }} \cdot I_{2 \text { mart }} \cdot\left(I / I_{2}\right)_{\text {mart }} \cdot\left(I / I_{\mathrm{c}}\right)_{\text {aust }}$

where $X_{\text {aust }}=1-X_{\text {mart }}$ and $X_{\text {mart }}$ are weight fractions of austenite and martensite phases, respectively.

\section{RESULTS}

Radio-graphical results show no visible cracks and porosity in the welded joint, which, according to EN ISO 5817:2014 [30] standard, was rated B class.

\subsection{Diffused and Residual Hydrogen Results}

Diffused and residual hydrogen test results are shown in Tab. 3. Very similar values were obtained with preheat temperatures of $150{ }^{\circ} \mathrm{C}$ and $160{ }^{\circ} \mathrm{C}$. Slightly lower values with a preheat temperature of $160{ }^{\circ} \mathrm{C}$ may be explained by the fact that as its value increases, the amount of diffusible hydrogen decreases.

\begin{tabular}{|c|c|c|c|}
\hline \multirow[b]{2}{*}{$\begin{array}{l}\text { Temperature/Type } \\
\text { of hydrogen level }\end{array}$} & \multicolumn{2}{|c|}{ Diffused hydrogen level } & \multirow[b]{2}{*}{$\begin{array}{c}\text { Residual } \\
\text { hydrogen } \\
\text { level }\end{array}$} \\
\hline & $\begin{array}{c}\text { Preheat } \\
\text { temperature } \\
1500^{\circ} \mathrm{C} \\
\end{array}$ & $\begin{array}{c}\text { Interpass } \\
\text { temperature } \\
160{ }^{\circ} \mathrm{C} \\
\end{array}$ & \\
\hline & $\mathrm{ml} / 100 \mathrm{gr}$ & $\mathrm{ml} / 100 \mathrm{gr}$ & $\mathrm{ml} / 100 \mathrm{gr}$ \\
\hline $400^{\circ} \mathrm{C}$ & 0.12 & 0.11 & 0.06 \\
\hline
\end{tabular}

\subsection{Tensile Testing Results}

While tensile characteristics were being tested, a fracture appeared in the weld metal. The tensile strength was $833 \mathrm{MPa}$, while the yield strength of $552 \mathrm{MPa}$ was within the expected limits, Fig. 6 . The difference between tensile and yield strength was $311 \mathrm{MPa}$, indicating a high ductility of the weld. Toughness was calculated from the area underneath the curve, and was $89 \mathrm{Jm}^{-3}$.

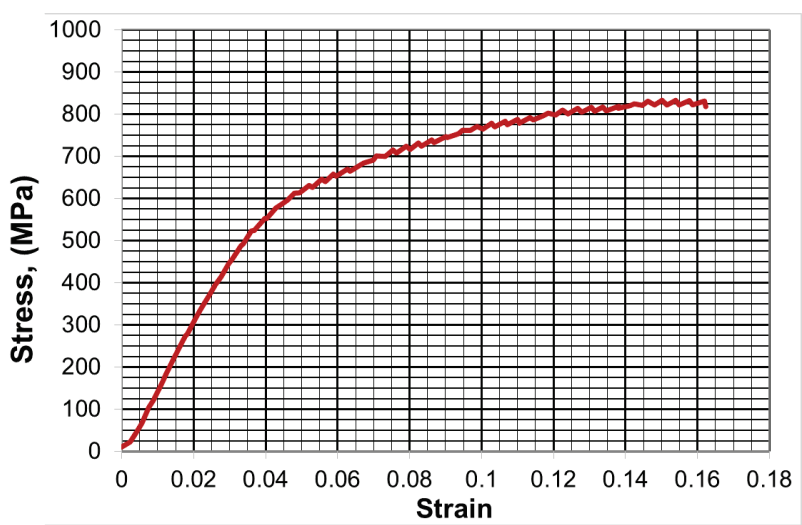

Figure 6 Stress-strain curve obtained from the base and weld metals transverse tensile testing

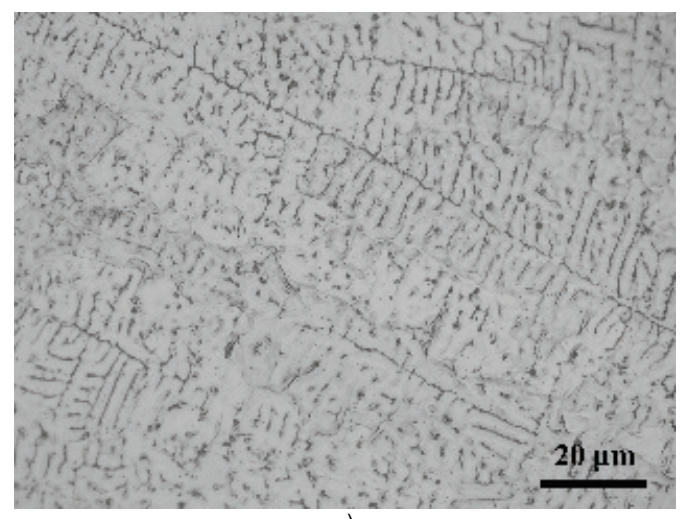

a)

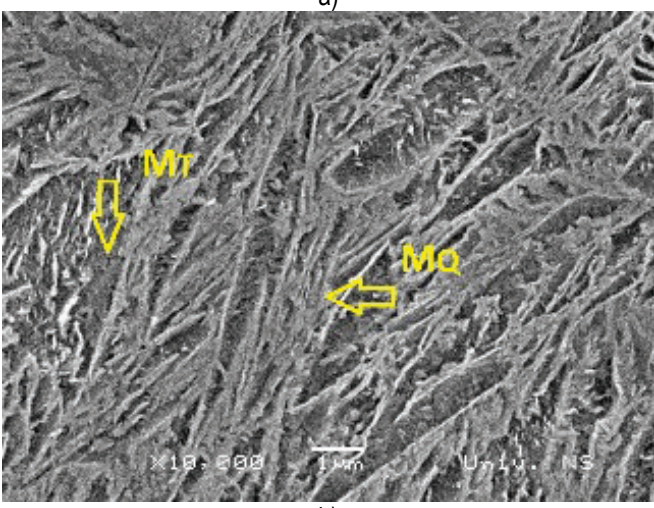

b)

Figure 7 a) Optical micrograph of AWS ER 307 filler; b) SEM micrograph of base material. $M_{T}$ - tempered martensite, $M_{Q}$ - quenched martensite

\subsection{Hardness and Microstructure Results}

The weld metal micrograph Fig. 7a) consists of austenite with delta ferrite. Delta ferrite becomes finer at lower heat input and cooling rate. In Fig. 7a), the uniformly distributed morphology of delta ferrite can be seen. The content of delta ferrite measured by Feritscope: in the weld root $11.7 \%$, in the center $5.4 \%$, in the upper part $3.2 \%$. The base metal micrograph Fig. 7b) in quenched and tempered condition consists of tempered and quenched martensite within the range of hardness 480-540 HB [21].

The hardness distribution from the top to the bottom, along the centerline of the weld metal, is shown in Fig. 8. The hardness value in the weld varies from 185 to $225 \mathrm{HV}$. 


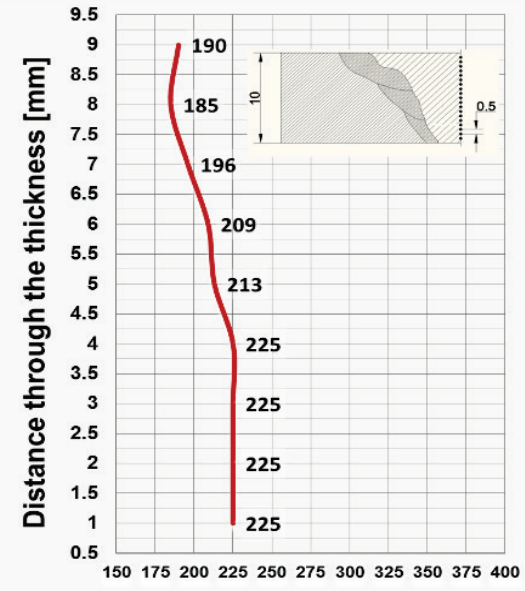

Microhardness HV 500 g

Figure 8 Hardness distribution at the center of the weld

\subsection{Fatigue Crack Growth Behavior}

Fig. 9 shows the crack growth rate in threshold region $d a / d N<10^{-4} \mathrm{~mm} /$ cycle. The threshold of stress concentration factor $\Delta K t h$ is $10 \mathrm{MPa} \mathrm{m}{ }^{1 / 2}$. The residual hydrogen content had no influence on the value of threshold stress concentration factor because of a small amount shown in Tab. 3.

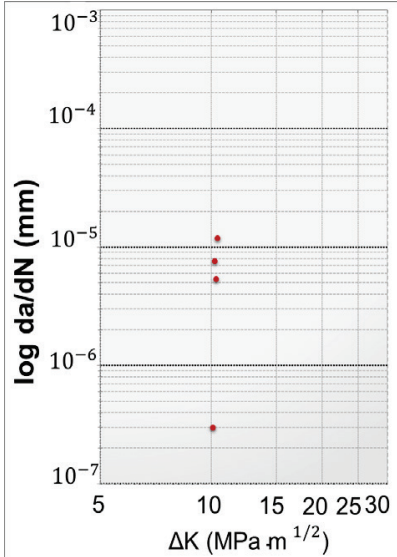

Figure 9 Fatigue crack growth rate per cycle, $d a / d N$, vs. stress intensity factor range, $\Delta K$, in the near threshold region. Specimens pre-cracked in weld metal, tested at room temperature.

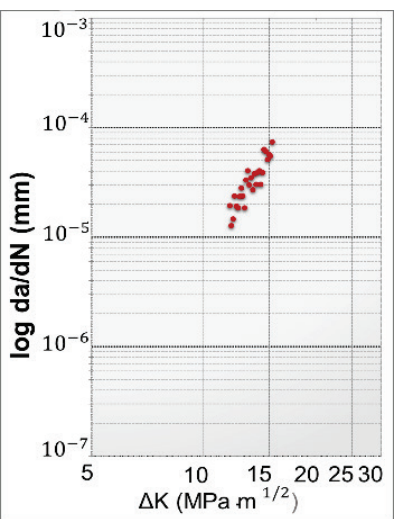

Figure 10 Fatigue crack growth rate per cycle, $d a / d N$, vs. stress intensity factor range, $\Delta K$, in the linear region

The crack growth rate in the region of linear growth $d a / d N>10^{-4} \mathrm{~mm} /$ cycle was shown in Fig. 10. The constants $C$ and $m$ in this region amount to $4 \times 10^{-11}$ and 5.3, respectively. The crack growth seen at the macro level is wavy and tortuous, Fig. 11.

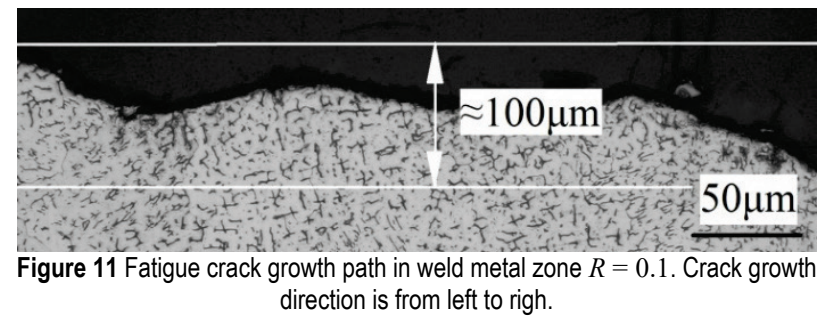

\subsection{Instrumented Charpy Impact Energies Results}

SEM fractographs of Charpy impact specimens fractured at $20^{\circ} \mathrm{C}$ are shown in Fig. 12 a) through c). The diagram presented in Fig. 12 a) was obtained, with a typically ductile fracture surface Fig. 12 b) and c). The measured impact energy for crack formation in this zone was $56 \mathrm{~J}$, with $29 \mathrm{~J}$ consumed for crack growth.

Table 4 Instrumented Charpy impact energy properties in the range of $20^{\circ} \mathrm{C}$ to

\begin{tabular}{|c|c|c|c|}
\hline $\begin{array}{c}\text { Test } \\
\text { temperature } \\
\left({ }^{\circ} \mathrm{C}\right)\end{array}$ & $\begin{array}{c}\text { Total absorbed } \\
\text { energy }(\mathrm{J})\end{array}$ & $\begin{array}{c}\text { Fracture } \\
\text { initiation } \\
\text { energy }(\mathrm{J})\end{array}$ & $\begin{array}{c}\text { Fracture } \\
\text { propagation } \\
\text { energy }(\mathrm{J})\end{array}$ \\
\hline 20 & 85 & 56 & 29 \\
\hline 0 & 68 & 43 & 25 \\
\hline-20 & 67 & 43 & 24 \\
\hline-40 & 62 & 41 & 21 \\
\hline
\end{tabular}

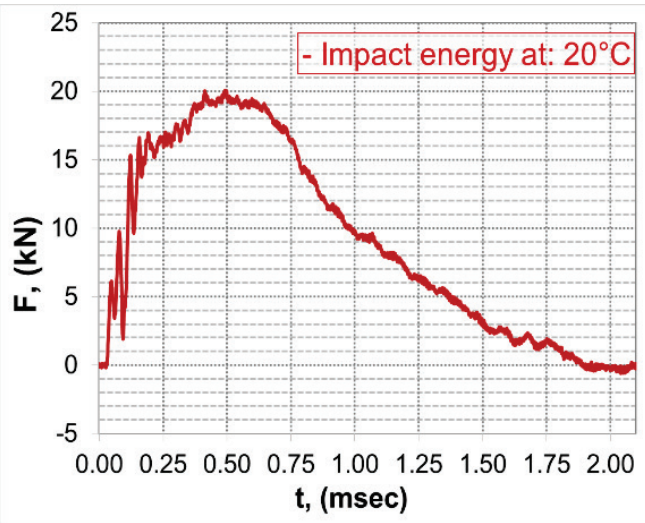

Figure 12 a) The load-time $(F-t)$ curve, recorded by oscilloscope at $20^{\circ} \mathrm{C}$

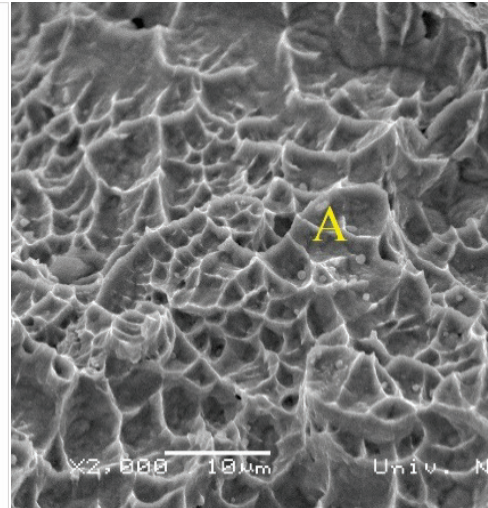

b) SEM fractograph of Charphy impact specimens, fractured at $20^{\circ} \mathrm{C}$

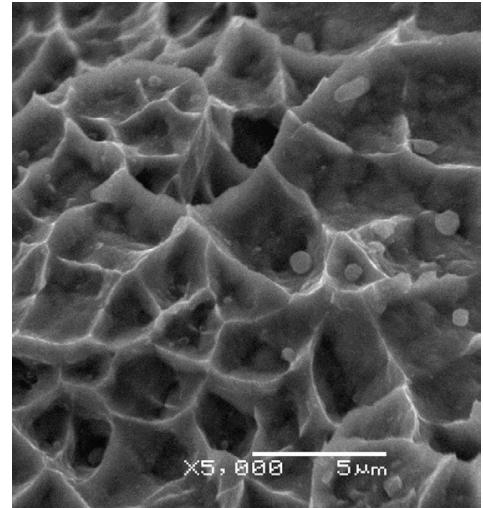

c) Enlarged part A, ductile fracture with deep dimples 


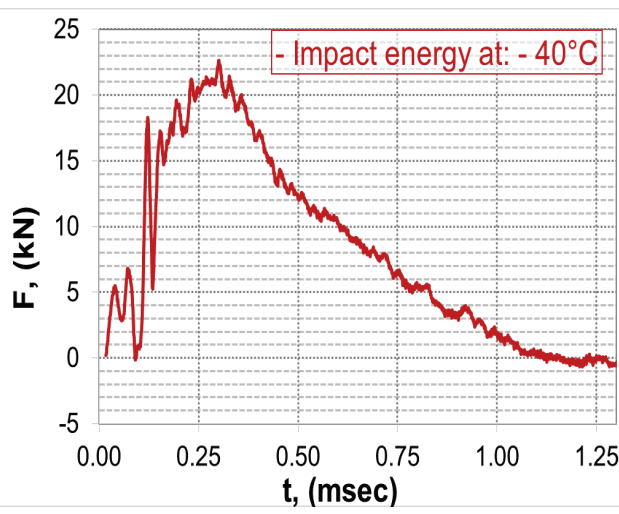

Figure 13 a) The load-time $(F-t)$ curve, recorded by oscilloscope at $-40^{\circ} \mathrm{C}$

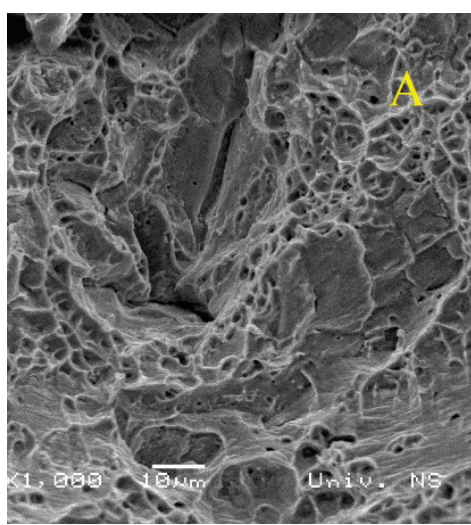

b) SEM fractograph of Charphy impact specimens, fractured at $-40{ }^{\circ} \mathrm{C}$

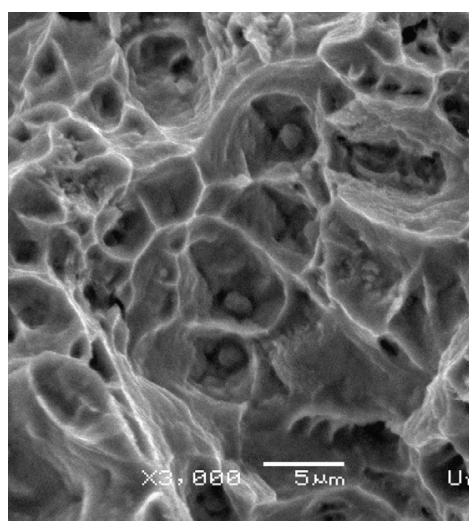

c) Enlarged part A, ductile fracture with deep and shallow dimples
SEM fractographs of Charpy impact specimens fractured at $-40^{\circ} \mathrm{C}$ are shown in Fig. 13 a) through c). The impact energy diagram shows a mixture of mainly ductile and slightly brittle fracture. A huge energy was consumed on the crack formation, $41 \mathrm{~J}$ and significantly less on the crack growth $21 \mathrm{~J}$.

\subsection{Fatigue Fractography Analysis}

Fig. 14 a) and b) show the fractograph in the crack growth threshold region in the weld metal zone. The fatigue striations are clearly visible on the fracture surface at $1 \mathrm{~mm}$ from the fatigue crack starting point and their size is about $3 \mu \mathrm{m}$.
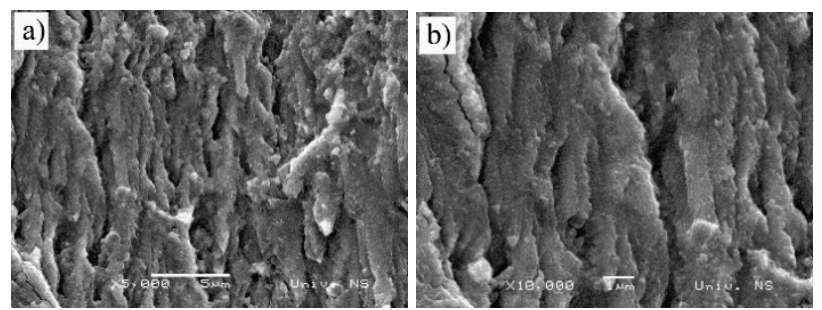

Figure 14 SEM fractography at $1 \mathrm{~mm}$ from the fatigue crack starting point

The fractrograph in the linear crack growth region is shown in Fig. 15 a) and b). The fatigue striations formed in this region are 4 to 5 times larger than in the threshold region, and are up to $15 \mu \mathrm{m}$ large.
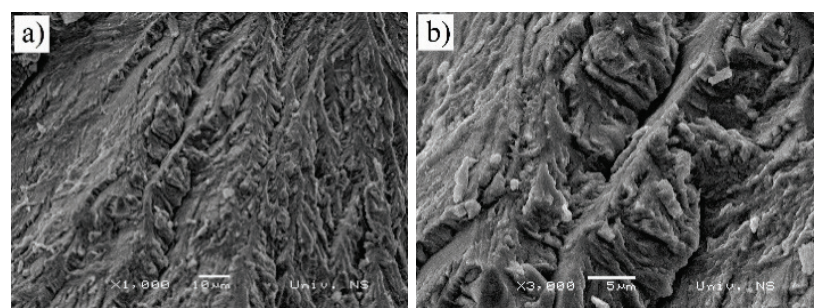

Figure 15 SEM fractography at $6.5 \mathrm{~mm}$ from the fatigue crack starting point

\subsection{XRD spectral analysis}

Fig. 16 shows the X-ray diffraction results of the deformation-induced $\alpha$ '-martensite. The changing amounts are shown per level, in relation to the fracture surface. The results show two phases, austenite and martensite. Both phases have two peaks, austenite with peaks of $2 \theta$ from 43.2-43.6 and 50.4-50.9, and martensite with its peaks at 43.5-44.2, 44.8 and 45.0 .
Since higher surface roughness causes increased diffuse X-ray scattering, peak intensities inversely correlate with the thickness of the specimens under investigation. Nevertheless, using the RIR method (reference intensity ratio), the ratio of integrated intensities of $\alpha$ '-martensite and austenite diffraction peaks reliably indicates their weight ratio in surface layers.

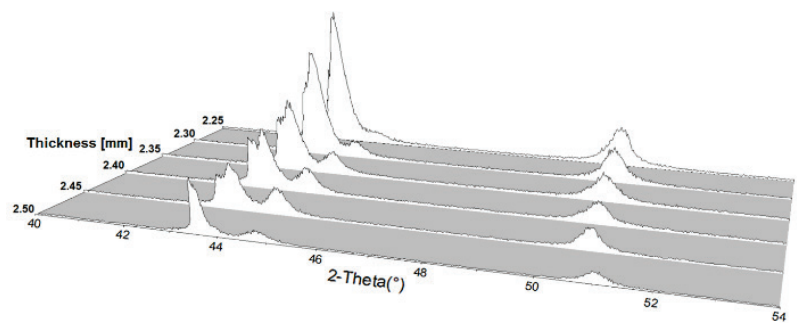

Figure 16 XRD Diffractograms of specimens under investigation

The most intense peaks of $\alpha$ '-martensite and austenite overlap not only in our specimen, but in numerous alloys published in crystallographic databases [26]. The uncertainty, inherent in heavily overlapping peaks deconvolution, makes them unsuitable for weight ratio determination. Therefore, the second most intense peaks were used. These peaks are only twice less intense than their stronger counterparts and therefore are absolutely sufficient for precise weight ratio calculation.

Table $5 \alpha$ '-Martensite volume fractions vs. specimen thickness

\begin{tabular}{|c|c|c|c|c|c|c|}
\hline & \multicolumn{5}{|c|}{$\alpha$ - Martensite volume fractions } \\
\hline Specimen thickness (mm) & 2.50 & 2.45 & 2.4 & 2.35 & 2.30 & 2.25 \\
\hline$\alpha^{\prime}$-Martensite volume (\%) & 55 & 50 & 46 & 34 & 30 & 24 \\
\hline Tolerance (\%) & \pm 3 & \pm 3 & \pm 2 & \pm 2 & \pm 2 & \pm 2 \\
\hline
\end{tabular}

Tab. 5 shows the changes percentage per level in relation to the fracture surface. $\alpha$ '-martensite was detected at distances up to $0.25 \mathrm{~mm}$ under the fracture surface. The greatest transformation of austenite into $\alpha$ '-martensite was $55 \%$, seen on the fracture surface. The amount of $\alpha$ 'martensite declines with a distance by an average of $\approx 5 \% / 0.05 \mathrm{~mm}$, in the depth perception tests. At the distance of $0.25 \mathrm{~mm}$, the amount of transformed austenite fell to $24 \%$.

Martensitic transformation took place due to plastic deformation at the crack tip. The plastic zone radius, according to Von Mises criterion Eq. (1), in the linear growth region, amounts to $r_{1 p}^{*}=0.14 \mathrm{~mm}$. 
$r_{1 p}^{*}=\frac{1}{4 \pi}\left(\frac{K_{\mathrm{I}}}{\sigma_{\mathrm{T}}}\right) \cdot\left(1+\frac{3}{2} \sin ^{2} \theta+\cos \theta\right), \mathrm{mm}$

Schram and Reed [31] established a formula for stacking fault energy calculation, an energy affecting a martensitic transformation possibility:

$S F E=-53+6.2(\% \mathrm{Ni})+0.7(\% \mathrm{Cr})+3.2(\% \mathrm{Mn})+9.3(\% \mathrm{Mo})(2)$

The stacking fault energy for austenitic filler material is $32 \mathrm{~mJ} / \mathrm{m}^{2}$. This slightly higher stacking fault energy results from the higher manganese and nickel content which exists in austenitic filler material.

\section{DISCUSSION}

It is known that welded joints are very heterogeneous, since they include weld metal, heat affected zone (HAZ) and base metal. Hardness is therefore defined by the zone of minimum hardness, which in the case of armor steel welding with austenitic filler material, is the weld metal zone. Armor steel welded joints are expected to have a tensile strength not lower than $550 \mathrm{MPa}$, in order to satisfy the requirements of MIL-STD-1185 [32]. The tensile strength achieved in this research of $833 \mathrm{MPa}$ is rather high for austenitic filler material and significantly higher than the tensile strength obtained by other authors [33]. The yield strength is slightly lower, but this is a higher ductility indication [34]. Fracture toughness total value from stress - strain curve, Fig. 6, is slightly higher than total energy value, obtained by instrumented pendulum impact given in Tab. 4. In both studies significantly more energy is required for the initiation relative to propagation of cracks.

The good combination of hardness and toughness is achieved by a very fine delta ferrite skeleton in the austenitic base. An average value of delta ferrite is $\approx 7 \%$. Delta ferrite is uniformly distributed and has potentially good mechanical properties: high impact energy, tensile strength and resistance to crack initiation. The cooling rate during the welding process and chemical composition of the filler material had an effect on an amount, shape and homogeneity of delta ferrite in the weld metal austenitic base. Delta ferrite becomes finer if the cooling rate decreases [35]. Cooling rate is affected by: heat input amount, preheat temperature and the thickness of the plate being welded. This research implemented a GMAW welding process characterized by a relatively high heat input of $2.1 \mathrm{~kJ} / \mathrm{mm}$, resulting in a slower cooling rate.

The base metal in welded joints of armor steel is always of higher hardness than the weld metal. This work examined welded joints with four passes, whereby no significant difference in hardness was observed in the root pass of the weld metal, with the lowest hardness obtained at the last pass. The change of hardness by weld metal depth was expected, and similar results were obtained in the same filler material [35], due to more intensive mixing of base and filler material in the first pass.

High impact energies at $-40{ }^{\circ} \mathrm{C}$ to $+20{ }^{\circ} \mathrm{C}$ were achieved with optimal hardness, as well as with high concentrations of nickel and manganese. The high energy of $56 \mathrm{~J}$ required for crack initiation is typical for extremely tough materials. Austenitic filler material showed a decrease of absorbed energy with a reduction in testing temperature. At the temperature of $-40{ }^{\circ} \mathrm{C}$, the impact energy required for crack initiation was significantly decreased, but still remained high. Higher value of impact energy than $84 \mathrm{~J}$ impact, in this paper, in relation to the same filler material in paper of Magudeeswaran [34], is expected, as it was announced in the previous tensile tests.

When welding these steels, there is a problem frequently arisen due to hydrogen retained in the weld metal. Higher hydrogen contents in welded joints increase the risk of hydrogen embrittlement, affecting the lifespan of welded constructions. A diffusible hydrogen amount in a weld metal falls with a preheat temperature increase. With a preheat temperature of $80{ }^{\circ} \mathrm{C}$, in paper [36] $0.5 \mathrm{mg}$ of hydrogen was obtained per $100 \mathrm{~g}$ of weld metal. In this work, the amount of residual and diffusible hydrogen at two times higher preheat temperature was significantly lower, and does not represent any danger for the welded joint. The use of austenitic solid wire as filler material was proved to be the right choice in this research.

Fatigue induced fracture depends on external factors such as load and internal factors such as mechanical properties of materials and microstructure. It is known that in stainless steel, being metastable materials, austenite transformation into martensite may occur during a fatigue crack growth; this is the result of intensive plastic deformation at the crack tip. X-ray diffraction showed the direct transformation of austenite into $\alpha$ '- martensite, what is typical for stainless steel with higher stacking fault energy. Martensitic transformation in these steels causes an increase in volume [37]. The resulting stress and strain fields which appear at the crack tip should be taken into account during determination of the stress intensity factor [38]. Phase transformations taking place at the crack tip [39] decrease the crack growth rate in the linear region [40]. Martensitic transformation takes place only in the thin layer close to the fracture surface. According to Eq. (1), the plastic zone in the region of linear growth has a radius of $0.14 \mathrm{~mm}$, which matches the X-ray diffraction results, showing that the zone of intensive martensitic transformation is at a depth of $0.1 \mathrm{~mm}$.

On the basis of transformed martensite percentage, it can be noticed the crack growth is rather difficult. Delta ferrite in the austenitic base of the weld metal gives rise to crack deflection and spreading, thus decreasing the stress intensity factor at the crack tip; it reduces the crack growth rate in this region.

It is known that microstructural characteristics are very important for fatigue crack growth; so, the coefficient defining the crack growth in the Paris region has slightly higher values than usual, which can be explained by the multi - pass weld having an irregular hardened microstructure.

In this research, the crack growth was normally monitored in respect to the growth direction of $\gamma$-austenitic dendrite. With regard to austenitic filler material and cast structure, slightly lower threshold values of stress concentration factor should be expected in the case of cracks growing in the direction parallel to the columnar grain [41]. 


\section{CONCLUSIONS}

On the basis of the results presented in this work, the following conclusions may be made:

1) Solid wire with a preheat temperature of $150{ }^{\circ} \mathrm{C}$ and inter-pass temperature of $160{ }^{\circ} \mathrm{C}$ can provide a low content of diffusible and residual hydrogen in the weld joint. Tensile strength of weld metal in the specimen welded with austenitic filler metal reached $833 \mathrm{MPa}$, which is greater than results published for the same filler metal in researches of manual welding.

2) Austenitic filler material shows a significant decrease in impact energy, followed by reduction in testing temperature. The results at room temperature showed high energies for crack initiation $56 \mathrm{~J}$ and propagation $29 \mathrm{~J}$. The results at $-40{ }^{\circ} \mathrm{C}$ indicate that significantly less energy is required for crack initiation $41 \mathrm{~J}$, while a small drop was observed for propagation $21 \mathrm{~J}$. During SEM analysis of the fracture surface, small high density dimples were clearly visible. Morphology of the fracture surface at $-40{ }^{\circ} \mathrm{C}$ indicates a mixed brittle ductile fracture.

3) An effect of the relatively high hardness combined with a high impact energy achieved by using austenitic filler material allows increased resistance to crack initiation with a fatigue crack threshold $\Delta K t h=10 \mathrm{MPa}$ $\mathrm{m}^{1 / 2}$, it results in better fatigue performance of the joint. Austenitic filler material showed high threshold stress concentration factor. Microscopic testing showed the rough fracture surface. The crack's growth path is very wavy and tortuous.

4) Direct transformation of $\gamma$-austenite into $\alpha$ '-martensite was ascertained in austenitic filler material AWS 307, with a fault energy of $32 \mathrm{~mJ} / \mathrm{m}^{2}$.

\section{Acknowledgements}

The authors would like to thank PhD Zijah Burzic, and Military Technical Institute for Mechanical Testing

This study was financially supported by the Ministry of Education, Science and Technological Development of the Republic of Serbia through the Project Nos. ON 174004.

This work was partly supported by the research grant no. OI171015 from the Ministry of Education, Science and Technological Development of the Republic of Serbia.

\section{REFERENCES}

[1] Atabaki, M. M., Ma, J., Yang, G., \& Kovacevic, R. (2014). Hybrid laser/arc welding of advanced high strength steel in different butt joint configurations. Mater. Des., 64, 573-587. https://doi.org/10.1016/j.matdes.2014.08.011

[2] Kuzmikova, L., Norrish, J., Li, H., \& Callaghan, M. (2011). Research to establish a systematic approach to safe welding procedure development using austenitic filler material for fabrication of high strength steel. $16^{\text {th }}$ International Conference on the Joining of Materials, 1-13.

[3] Alkemade, S. J. (1996). The Weld Cracking Susceptibility of High Hardness Armour Steel, Australia, 1-24.

[4] Magudeeswaran, G., Balasubramanian, V., \& Madhusudhan, R. G. (2008). Effect of welding processes and consumables on high cycle fatigue life of high strength, quenched and tempered joints. Mater. Des., 29, 1821-1827. https://doi.org/10.1016/j.matdes.2008.03.006
[5] Ranjbarnodeh, E., Pouraliakbar, H., \& Kokabi, A. H. (2012) Finite Element Simulation of Carbide Precipitation in Austenitic Stainless Steel 304. Int. J. Mech. Applic., 2, 117123. https://doi.org/10.5923/j.mechanics.20120206.03

[6] Alam, M. M., Barsoum, Z., Jonsén, P., Kaplan, A. F. H., \& Häggblad, H. Å. (2011). Influence of defects on fatigue crack propagation in laser hybrid welded eccentric fillet joint. Eng. Fract. Mech., 78, 2246-2258. https://doi.org/10.1016/j.engfracmech.2011.04.011

[7] Khorrami, M. S., Mostafaei, M. A., Pouralakbar, H., \& Kokabi, A. H. (2014). Study on microstructure and mechanical characteristics of low-carbon steel and ferritic stainless steel joints. Mater.Sci. Eng. A, 608, 35-45. https://doi.org/10.1016/j.msea.2014.04.065

[8] Cimpoeru, S. J. (1993). The Measurement of Dynamic Structural Stresses in a Light Armoured Vehicle. M. Eng. Sci, GradieAust, In the 5th Australian Aeronautica Conference, Melbourne, 13-15.

[9] Shah Khan, M. Z., Alkemade, S. J., Weston, G. M., \& Wiese, D. G. (1998). Variable-amplitude fatigue testing of a high hardness armour steel. Int. J. Fatigue, 20(3), 233-239. https://doi.org/10.1016/S0142-1123(97)00112-6

[10] Pouraliakbar, H., Hamedia, M., Kokabia, A. H., \& Nazari, A. (2014). Designing of CK45 Carbon Steel and AISI 304 Stainless Steel Dissimilar Welds. Mater. Research, 17, 106114. https://doi.org/10.1590/S1516-14392013005000170

[11] Enrico, L. (2016). Estimating dynamic ultimate tensile strength from instrumented Charpy data. Mater. Des., 97, 437-443. https://doi.org/10.1016/i.matdes.2016.02.116

[12] Martelo, D. F., Mateo, A. M., \& Chapetti. M. D. (2015). Fatigue crack growth of a metastable austenitic stainless steel. Int. J. Fatigue, 80, 406-416. https://doi.org/10.1016/j.ijfatigue.2015.06.029

[13] Shang, Y. B., Shi, H. J., Wang, Z. X., \& Zhang, G. D. (2015). In-situ SEM study of short fatigue crack propagation behavior in a dissimilar metal welded joint of nuclear power plant. Mater. Des., 88, 598-609. https://doi.org/10.1016/j.matdes.2015.08.090

[14] Feng, X. \& Yong, L. (2007). Effect of stress-induced martensitic transformation on the crack tip stress-intensity factor in Ni-Mn-Ga shape memory alloy. Acta Mater., 55, 5621-5629. https://doi.org/10.1016/j.actamat.2007.06.031

[15] Martelo, D. F., Mateo, A., \& Chapetti, M. D. (2015). Crack closure and fatigue crack growth near threshold of a metastable austenitic stainless steel. Int. J. Fatigue, 77, 6477. https://doi.org/10.1016/j.ijfatigue.2015.02.016

[16] Moallemi, M., Kermanpur, A., Najafizadeh, A., Rezaee, A., Baghbadorani, S. H., \& Nezhadfar, D. P. (2016). Deformation-induced martensitic transformation in a 201 austenitic steel. The synergy of stacking fault energy and chemical driving force. Mater.Sci. Eng. A, 653, 147-152. https://doi.org/10.1016/j.msea.2015.12.006

[17] Allain, S., Chateau, J. P., Bouaziz, O., Migot, S., \& Guelton, N. (2004). Correlations between the calculated stacking fault energy and the plasticity mechanisms in $\mathrm{Fe}-\mathrm{Mn}-\mathrm{C}$ alloys. Mater. Sci. Eng., 387-389, 158-162. https://doi.org/10.1016/..msea.2004.01.059

[18] Remy, L. \& Pineau, A. (1977). Twinning and strain-induced $\mathrm{FCC} \rightarrow \mathrm{HCP}$ transformation in the $\mathrm{Fe}-\mathrm{Mn}-\mathrm{Cr}-\mathrm{C}$ system. Mater. Sci. Eng., 28, 99-107. https://doi.org/10.1016/0025-5416(77)90093-3

[19] Mei, Z. \& Morris, J. W. (1990). Influence of deformationinduced martensite on fatigue crack propagation in 304-type steels. Metall Trans, A, 21(12), 3137-3152. https://doi.org/10.1007/BF02647310

[20] Gangloff, R. P. (2003). Hydrogen assisted cracking of high strength alloys. In: Milne, I., Ritchie, R. O., Karihaloo, B., Petit, J., Scott, P., editors. Compr. Struct. Integ. New York: Elsevier Science, 31-101. https://doi.org/10.1016/B0-08-043749-4/06134-6 
[21] Cabrilo, A. \& Geric, K. (2016). Weldability of High hardness armour steel. Advan. Mater. Research, 1138, 7984. https://doi.org/10.4028/www.scientific.net/AMR.1138.79

[22] Tsay, L. W., Liu, Y. C., Young, M. C., \& Lin, D. Y. (2004). Fatigue crack growth of AISI 304 stainless steel welds in air and hydrogen. Mater. Sci. Eng. A, 374, 204-210. https://doi.org/10.1016/j.msea.2004.02.018

[23] EN ISO 3690:2012. Welding and allied processes. Determination of hydrogen content in arc weld metal.

[24] Monazzah, A. H., Pouraliakbar, H., Bagheri, R., \& Reihani. S. M. S. (2014). Toughness behavior in roll-bonded laminates based on AA6061/SiCp composites. Mater. Sci. Eng. A, 598, 162-173. https://doi.org/10.1016/j.msea.2014.01.014

[25] ASTM E647-08:2004. Standard test method for measurement of fatigue crack growth rates. In Annual Book of ASTM Standards, Volume 03.01, West Conshohocken (PA): ASM International.

[26] Snyder, R. L. (1992). The Use of Reference Intensity Ratios in X-Ray Quantitative Analysis. Powder Diffraction, 7, 186193. https://doi.org/10.1017/S0885715600018686

[27] ICDD, PDF-2 (Database), \#44-1293. (2003). International Centre for Diffraction Data, Newtown Square, PA, USA

[28] Arbuzov, M., Golub, S. Y., \& Karpets, M. (1986). Structure of austenite ordering in chromium steels. FizikaMetallov $i$ Metallovedenie, 62, 108-111.

[29] Amar. K. D., David, C., Murdock, C. M., Speer, J. G., \& Matlock, K. D. (2004). Quantitative measurement of deformation-induced martensite in 304 stainless steel by Xray diffraction. Scr. Mater., 50, 1445-1449. https://doi.org/10.1016/j.scriptamat.2004.03.011

[30] EN ISO 5817:2014.Welding. Fusion-welded joints in steel, nickel, titanium and their alloys (beam welding excluded). Quality levels for imperfections.

[31] Scharam, R. E. \& Reed, R. P. (1975). Stacking fault energies of austenitic stainless steels. Metall Trans A, 6A, 1345-1351. https://doi.org/10.1007/BF02641927

[32] MIL-STD-1185:2008. Department of defense manufacturing process standard: welding, high hardness armor, [SUPERSEDES MIL-W-62162].

[33] Magudeeswaran, G. \& Balasubramanian, V. R. (2014). Effect of welding processes and consumables on fatigue crack growth behaviour of armour grade quenched and tempered steel joints. Def. Techn., 10, 47-59. https://doi.org/10.1016/j.dt.2014.01.005

[34] Magudeeswaran, G., Balasubramanian, V., Madhushudan, R. G., \& Balasubramanian, T. S. (2008). Effect of Welding Processes and Consumable on Tensile and Impact properties of High Strength Quenched and Tempered Steel Joints. J. Iron Steel Res. Int., 15(6), 97-94. https://doi.org/10.1016/S1006-706X(08)60273-3

[35] Murti, V. S. R., Srinivas, P. D., Banadeki, G. H. D., \& Raju, K. S. (1993). Effect of heat input on the metallurgical properties of HSLA steel in multi-pass MIG welding. $J$. Mater. Process. Technol., 37, 723-729. https://doi.org/10.1016/0924-0136(93)90131-0

[36] Kuzmikova, L. (2013). An investigation of the weldability of high hardness armour steels. PhD Thesis, Faculty of Engineering, University of Wollongong, Australia.

[37] Haušild, P., Davydov, V., Drahokoupil, J., Landa, M., \& Pilvin, P. (2010). Characterization of strain-induced martensitic transformation in a metastable austenitic stainless steel. Mater. Des., 31, 1821-1827. https://doi.org/10.1016/..matdes.2009.11.008

[38] Xiong, F. \& Liu, Y. (2007). Effect of stress-induced martensitic transformation on the crack tip stress-intensity factor in Ni-Mn-Ga shape memory alloy. Acta Mater., 55, 5621-5629. https://doi.org/10.1016/j.actamat.2007.06.031

[39] Nakajima, M., Akita, M., Uematsuc Y., \& Tokaji, K. (2010). Effect of strain-induced martensitic transformation on fatigue behavior of type 304 stainless steel. Procedia Eng., 2, 323-330. https://doi.org/10.1016/.proeng.2010.03.036

[40] Grujicic, M., Lai, S. G., \& Gumbsch, P. (1997). Atomistic simulation study of the effect of martensitic transformation volume change on crack-tip material evolution and fracture toughness. Mater. Sci. Eng. A, 231, 151-162. https://doi.org/10.1016/S0921-5093(97)00068-3

[41] Shang, Y. B., Shi, H. J., Wang, Z. X., \& Zhang, G. D. (2015). In-situ SEM study of short fatigue crack propagation behavior in a dissimilar metal welded joint of nuclear power plant. Mater. Des., 88, 598-660.

https://doi.org/10.1016/j.matdes.2015.08.090

\section{Contact information:}

Aleksandar CABRILO, MSc

Faculty of Technical Sciences, University of Novi Sad

Trg Dositeja Obradovica 6, 21000 Novi Sad, Serbia

E-mail: cabrilo@uns.ac.rs

Katarina GERIC, PhD

Faculty of Technical Sciences, University of Novi Sad

Trg Dositeja Obradovica 6, 21000 Novi Sad, Serbia

E-mail: gerick@uns.ac.rs

Olivera KLISURIC, PhD, Assoc. Prof.

Academy of Arts, Faculty of Technical Sciences,

University of Novi Sad,

Trg Dositeja Obradovica 6, 21000 Novi Sad, Serbia

E-mail: olivera.klisuric@df.uns.ac.rs

Miroslav CVETINOV, PhD, Assoc. Prof.

Academy of Arts, Faculty of Technical Sciences, University of Novi Sad,

Trg Dositeja Obradovica 6, 21000 Novi Sad, Serbia

E-mail: miroslav.cvetinov@df.uns.ac.rs 